\title{
Synthesis, Analysis and Thermoelectrochemical Applications of Ionic Liquids
}

\section{Fatma SARF*}

Physics Department, Çanakkale Onsekiz Mart University, Turkey

*Corresponding author: Fatma SARF, Physics Department, Çanakkale Onsekiz Mart University, Çanakkale, Turkey, Tel: +902862180018/1942; Email: fatmaozutok@comu.edu.tr

\section{Research Article}

Volume 4 Issue 2

Received Date: April 15, 2019

Published Date: April 25, 2019

DOI: $10.23880 /$ nnoa-16000159

\section{Abstract}

New materials, which are eco-friendly and have unusual characters, are so attractive with the increasing demand and harmful pollutants amount all over the world. As a solvent, non-evaporate ionic liquids (ILs) have recently captured notable interest due to their magnifical properties. They have been used for distinct purposes such as electrochemistry, separation, lubrication, catalyst, and energy applications. Adding functional groups and/or anion or cation tunability can ensure improved efficiency ILs depends on the application type. The preset paper is primarily focused on the ionic liquids (IL) synthesis, development of functionalized ionic liquids, and their purification process. It also provides a review of the use of ionic liquids as electrolytes in the thermoelectrochemical cells due to the immediate necessity in areas ranging from waste heat conversion to electricity in modern life. Because ionic liquids have hazardous environmental effects, incur high costs, and require complex synthesis and purification process, all must be under control, recovered and optimized. Therefore, understanding their nature has become more important. Additionally, viscosity and conductivity of ILs are an obstacle in experimental studies; besides, the use of redox couples in IL electrolytes must be improved to use in thermoelectrochemical cell applications.

Keywords: Ionic liquid; Purification; Functionalization; Synthesis; Analysis; Thermoelectrochemical

\section{Introduction}

Ionic liquids (ILs) are defined as a multipurpose salt forming ion pairs with melting points below $100{ }^{\circ} \mathrm{C}$ or sometimes at or around room temperature (RT). Ion pairs generally consist of asymmetric organic cations (e.g. pyridinium, imidazolium, alkylphosphonium or alkylammonium ions) and weakly coordinating inorganic/organic anions. In ILs, anions and cations have been connected with strong Columbic interactions in the free movement charge field unlike conventional salts [1]. Other chemical interactions such as hydrogen bonding and van-der-Waals interactions between ions are very important to determine IL structure [2,3]. The main reason for liquidity of ILs at RT is the fact that ionic interactions with small lattice enthalphies reduce due to inorganic ions replaced with large sized organic ions [4]. They are called molten salts, neoteric solvents, designer solvents, green solvents, liquid electrolytes, ionic fluids, fused organic salt, eco-friendly solvents, greener selects, third group of solvents, etc. [5,6]. Hazards of ILs have not been identified on the living body; therefore, contact with skin, eyes, and any other body parts should be avoided [7]. 


\section{Nanomedicine \& Nanotechnology Open Access}

Nature and cation-anion design of ILs can primarly affect their acidity-basicity and hydro-characteristics.
Depending on this classification, ILs may be categorized as in Table 1.

\begin{tabular}{|c|c|c|}
\hline Type of IL & Example & References \\
\hline \multirow{2}{*}{ Hydrophobic } & 1-alkyl-3-methylimidazolium ions with hexafluoro-acetylacetonate anions & Mehdi, et al. [8] \\
\hline & $\left.\mathrm{N}\left(\mathrm{SO}_{2} \mathrm{CF}_{3}\right)_{2}^{-}\left(\mathrm{NTf}_{2}^{-}\right)\right)^{2,3}$ & Bhatt [9] \\
\hline \multirow{2}{*}{ Hydrophilic } & 1-Ethyl-3-methylimidazolium ions with choline & Hayakawa, et al. [10] \\
\hline & 2-methacryloyloxy ethyl with trimethyl-ammonium chloride & Jiao, et al. [11] \\
\hline \multirow{2}{*}{ Acidic } & 1-(3-propylsulfonic)-3-methylimidazolium chloride & Amarasekara [12] \\
\hline & 1-(4-butylsulfonic)-3-methylimidazolium hydrogensulfate & Amarasekara [12] \\
\hline \multirow{2}{*}{ Basic } & 3-amino-propyl-tributyl-phosphonium glycine & Hajipour, et al. [13] \\
\hline & 1-butyl-3-methylimidazolium hydroxide & Hajipour, et al. [13] \\
\hline \multirow{2}{*}{ Neutral } & Hexafluorophosphate & Li, et al. [14] \\
\hline & bis(trifluoromethanesulfonyl)amide & Kimble, et al. [15] \\
\hline
\end{tabular}

Table 1: Classification of ILs depending on their acidity-basicity and hydro-characteristics.

Because of their tunable and unique properties, they can arouse much more interest in research and development of media activities. These properties can be listed as follows:

1. good thermal stability (up to $400^{\circ} \mathrm{C}$ )

2. high chemical stability

3. polarity

4. non-volatility

5. dissolvability

6. non-flammability

7. wide electrochemical potential window

8. viscosity

9. adjustable miscibility

10. high gas solubility to separate gases

11. less toxicity than conventional salts

The most important property of ILs is the fact that their negligible vapor pressure causes a replacement of volatile organic solvents in organic reactions, supplying a huge contribution of green chemistry compared to traditional solvents. Additionally, they ensure a good control over all chemical processes especially in the catalysis. These properties make them different compared with water or organic solvents.

Ionic liquids are characterized by the structural design of anions and cations, structural functionalization of their side chains, and/or mixture of two or more ILs. Especially anion alteration exerts an effect on the physicochemical properties such as viscosity, density, conductivity, and melting point [16]. In order to obtain more specific and intended ILs, arrangement of new ion families (approximately $10^{18}$ as assumed) and understanding ILs' interactions with other species are mandatory [17]. Besides, purification and functionalization are necessary steps to develop task-specific ILs.
There are many industrial fields to use ILs in as a technological material. Some are showed in Figure 1 Their applications can become diversified over the years with the increasing demand and amount of functionalized ILs [18]. They can be divided further into subcategories in themselves such as separation (gas separation, extractive distillation, extraction, etc.), electrochemistry (batteries, fuel cells, solar panels, metal plating, double layer capacitors, sensors, electro-optic devices, etc.), pharmaceutical (vaccination, drug delivery, active pharmaceutical ingredients, perfume, etc.) and green chemistry (water splitting, green solvents, high-energy materials, thermoelectro-chemical cells, fuel additives, bio-ionic liquids, capturing of $\mathrm{CO}_{2}, \mathrm{SnO}_{2}, \mathrm{H}_{2} \mathrm{~S}, \mathrm{CO}$, or $\mathrm{NO}_{\mathrm{x}}$ etc.) $[19,20]$. Out of these applications, the use of IL as a solvent is widespread in different type chemical reactions such as Diels-Alder, Friedel-Craft, Heck, hydration, oxidation, alkylation, hydroformulation, esterification, dimerization, polymerization, etc [21].

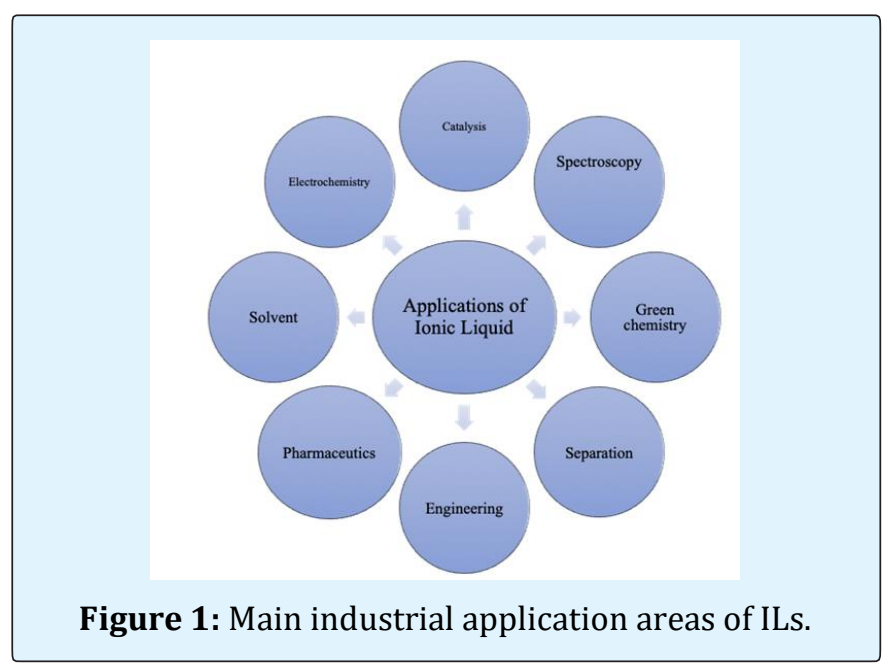




\section{Nanomedicine \& Nanotechnology Open Access}

Although ILs have a considerable variety of applications, their production strikingly limited, which arises from some adverse properties that they have. Thanks to their potential allowing for varied structural designs, each IL has characteristic solvent properties accompanied by several advantages and disadvantages. For example, mass production results in decreased outlay, but purification is a crucial issue in this procedure. Limitations and disadvantages of ILs may be listed as low biodegradability, ecotoxicity, biocompatibility, high viscosity, sustainability, and cost in the practical applications [22]. These complications are dependent on the cation and anion types/natures and the length of alkyl side chains. When standard OECD tests are run to determine biodegradability, short alkyl chains can cause a decrease in the microbiological decomposition [23]. Additionally, hydrolyzable groups, oxidized groups, and carboxylic acids affect the biodegradability level of ILs [24]. As explained by Mutabil, longer cation alkyl chain length adversely affects toxicity of microorganisms, e.g. marine bacterium V. fischeri [25]. Trophic level of the test organisms determines the susceptibility of ILs [26].

In order to reduce production cost of ILs in the industry, they are mixed with other proper materials, such as cellulose, carbon nanotube, epoxy resin, polymers, etc [27]. Additionally, another problem concerned with ILs is that they are petroleum derivatives. Therefore, biobased ILs have been increasingly synthesized recently [28].

In the history of ILs, the first synthesized ionic liquid was ethanolammonium nitrate, reported by Gabriel and Weiner in 1888 [29]. The first protic IL at RT was ethylammonium nitrate with a melting point of $12{ }^{\circ} \mathrm{C}$, which was reported by Walden in 1914 [30]. Back then, this topic did not receive much attention from the scientific community because of its instability, poor solubility in water, and limited application areas. Binary ILs (aluminum (III) chloride with $\mathrm{N}$ alkylpyridinium) challenged and broke down this prejudice [31]. Between the 1960s and 1980s, electrolytes containing ionic liquids in battery cells were developed by U.S. Force Academy by using the conductivity nature of chloroaluminate-based ionic liquids with pyridinium or imidazolium cations as known dual intercalating molten electrolyte [32].

After the $1^{\text {st }}(1980 s)$ and $2^{\text {nd }}(1990 s)$ generation stable ILs were discovered in water and air, the $3^{\text {rd }}$ generation (2000s) ILs called as task-specific ILs were developed by Davis, et al. based on organic cations that were extracted from miconazole, an antifungal agent [33]. Chemical reactions involving imidazole quaternization and anion metathesis were used to synthesize the $1^{\text {st }}$ and $2^{\text {nd }}$ generation ionic liquids, respectively. ILs through the separation of $\mathrm{CO}_{2}$ from gas streams have been investigated since 1999 [34]. Nanotechnological application (Pd-nanoparticle) of ILs was first observed by transmission electron microscopy (TEM) as described by Srinivasan, et al. [35]. In 2002, ionic liquid functionalization protocol was first reported by Zhaou with a specific reference to functional groups in the cation [36]. Dai, et al. were the first to use ILs as a solvent [37]. Moreover, polymer science and green chemistry applications of ILs have been studied since 1998 and 2004, respectively [38]. These mark milestones in ILbased technology. The first functional 1,1,3,3tetramethylguanidinium lactate ([TMG]L) was synthesized by $\mathrm{SnO}_{2}$ capturing in 2004 [39]. Ionic liquid crystals in flexible electronics and ion gels have attracted substantial attention particularly in the last years.

\section{Synthesis and Analysis of Ionic Liquids}

The type of synthesis is gravely important to obtain the desired ILs. They can be utilized in very different ways such as homogeneously, heterogeneously, multiphase, and in bio-transformations and in organo-catalysis. Until now, many research groups have investigated IL synthesis routes by using different methods.

There are three basic chemical reactions to prepare ILs as shown in Figure 2:

a) Metathesis reaction: After the cation design, anion exchange is performed by a metathesis exchange reaction by using metal salts (silver nitrate, silver thiocyanate) or Brønsted acid to obtain alkylammonium, pyridinium and imidazolium halides. It is probable that the most preferred method for the synthesis of ionic liquids is metathesis reaction. They are equilibriumcontrolled, reversible, and under kinetic control [40]. A small amount of impurities occurred after this reaction, which may react with solute materials. In equation (1) related to metathesis reaction, $\mathrm{M}[\mathrm{Y}]$ is inorganic metal salt, $\mathrm{H}[\mathrm{Y}]$ is conjugate acid of the desired anion, and $\mathrm{NH}_{4}[\mathrm{Y}]$ is ammonium salt

Cation $[\mathrm{X}]+\mathrm{M}[\mathrm{Y}] / \mathrm{H}[\mathrm{Y}] / \mathrm{NH}_{4}[\mathrm{Y}] \rightarrow$ Cation $[\mathrm{Y}]+$ $\mathrm{M}[\mathrm{X}] / \mathrm{H}[\mathrm{X}] / \mathrm{NH}_{4}[\mathrm{X}]$ (1)

b) Acid-base neutralization: This procedure is very simple, non-contaminated, and inexpensive. It is known that ILs consist of proton acceptor and proton donor sites and stronger acids have much more effects on the proton transfer than bases. Protic ILs are generally prepared by neutralization with proton transfer between 


\section{Nanomedicine \& Nanotechnology Open Access}

a Bronsted acid and a Bronsted base according to Equation 2:

$$
\left(\mathrm{CH}_{3}-\mathrm{CH}_{2}\right)_{3} \mathrm{~N}+\mathrm{AH} \leftrightarrow\left(\mathrm{CH}_{3}-\mathrm{CH}_{2}\right)_{3} \mathrm{~N}+\mathrm{NH}^{+} \mathrm{A}^{-} \text {(2) }
$$

In protic ILs, neutralization produces active protons, having H-bonds. Near-pure organic tertiary amines with halide acids or some organic acids may be obtained by acid-base neutralization. As explained by Kirchner, acid/base equilibrium is so important in neutralization such as an anion amino acid with $\left[\mathrm{C}_{2} \mathrm{mim}\right][\mathrm{OH}]$ reacted by neutralization [41]. Liu, et al. reported that the electronic environment of the anion could be tuned with the increased basicity of the anion or acidity of the cation [42]. c) The reaction of imidazole carbenes as strong bases: Imidazole-based ILs have no N-H bonds and are reactive towards basic salt, potassium, and bases. Imidazolium cation are conjugate acid-base couples and carbene acts as a base and regenerates its parent ion. Non-contaminated ILs with halide ions or metal ions may be obtained by using imidazole carbenes [43]. Alcohols, carbonic acid, acetic acid, and alkyl sulphonic acid are used to carry out this reaction process. In some reviews, metathesis reaction and acid-base neutralization are considered due to the lack of data about imidazole carbenes reaction [44].

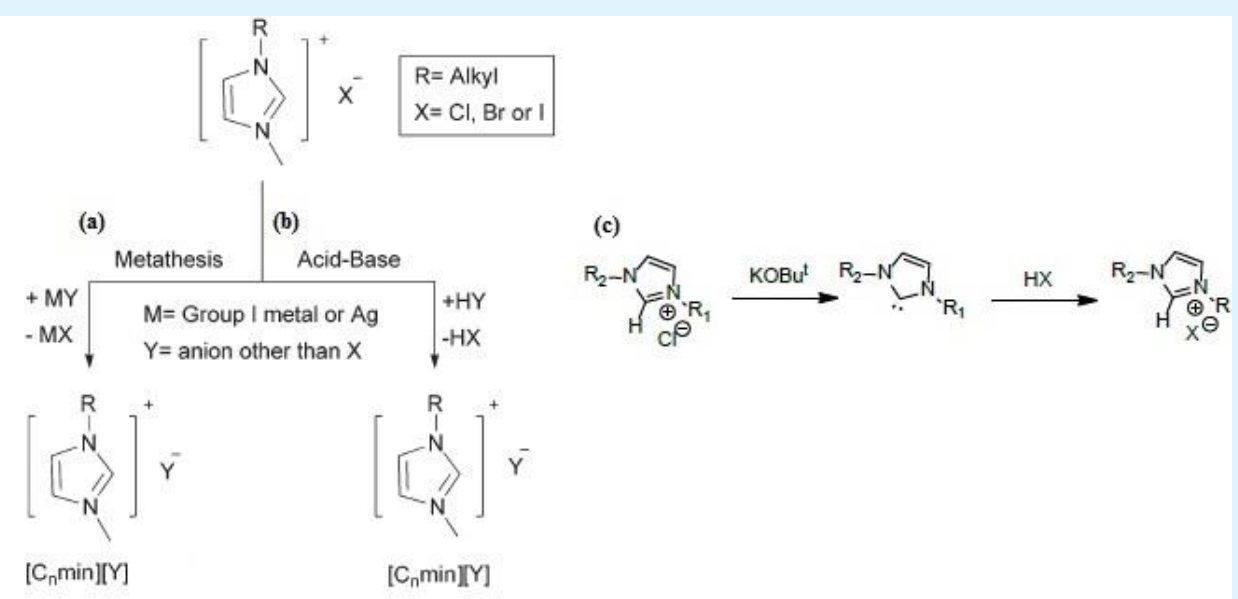

Figure 2: Basic chemical reactions to prepare ILs: a) metathesis reaction, b) acid-base neutralization and c) reaction of imidazole carbenes. Reprinted with permission from Ferraz, et al. [44] and Srour, et al. [45].

In general, IL synthesis consists of two stages except for cation and anion formation from their starting materials, called as 'simple salts' or '2nd generation ILs', as in Equation 3;

Lewis Base $\rightarrow^{\mathrm{D}}[\mathrm{Cat}]^{+}[\mathrm{A}]^{-}$; D: triflate, tosylate (for direct synthesis) (3)

Cation Design (Imidazole quaternization): There are two types of cation synthesis: one is protonation of an amine by a free acid and the other is quaternization reactions of amine or phosphine. The described main cations are imidazolium, pyridinium, pyrazolium, pyrrolidinium, ammonium, phosphonium, and cholinium. Sometimes, only quaternization reactions are enough for IL synthesis. They generally do not contain acidic protons. Recently, cation-based ILs have become an attractive subject due to the ton-scale production opportunity in the industry, inexpensiveness in the preparation step, and thermal/chemical stability [46]. The most used cation design alkylation reaction is 1-methylimidazole, which includes cheap haloalkanes and requires relatively mild temperatures. Besides, it contains specifically halide impurities, which reduce catalyst performance of ILs. Imidazolium compounds contain cations such as 1-ethyl3-methylimidazolium [C2mim]+ or 1-butyl-3methylimidazolium [C4mim]+ that make ILs stable and possess low melting points and high viscosities, as reported by Depuydt, et al. [47]. In the use of alkly halides in quaternization reactions, alkly chain length and reactivity of the halide determine reaction rate [48].

Anion Design (anion metathesis): Anion formation can be carried out by treating halide salts with Lewis acids or 


\section{Nanomedicine \& Nanotechnology Open Access}

by anion metathesis. The most common types of anions are halides, nitrate, chloroaluminates, hexafluorophosphate, tetrafluoroborate, alkyl sulphate, alkylcarboxylates, tosylate, triflate, discyanamide, tristrifluorophosphate, metal complexes, etc. Symmetrical tetraalkylammonium salts and trialkylsulfonium iodide are the samples which can be produced by this process alone. In Lewis acidic ILs, the molar excess of $\mathrm{AlCl}_{3}$ can determine the type of acidic, basic or neutral IL where $\mathrm{AlCl}_{3}$ is the most preferred.

IL synthesis properties, which contain the appropriate combination of cations and anions, may be listed as below:

- The reaction time should be short.

- The reaction should not be multi-step.

- The reaction medium must be designable.

- The yield should be high.

- The need for starting material should be minimal.

- It should be environmentally friendly and safe.

- Impurities such as halides, protic impurities, water, etc. should be minimal.

- In the catalyst applications, the catalysts may be recovered and reused several times.

Classical conventional methods via quaternization of amines were employed in the stirred tanks. This was time-consuming. The highest starting material demand occurred under high vacuum condition. Additionally, solvents were highly needed due to the purification of ILs. Therefore, research groups tried other successful methods. Microwave assisted preparation in solvent and solvent-free medium have been used by many researchers since 2001 [49]. The quaternization reaction have been improved by the use of microwave by heating reactants and superheating solvents to a temperature well in excess of their normal boiling points [50]. Ultrasonic irradiation is another option for synthesis of ILs. Ultrasonic irradiation includes simplicity, lower costs, decreased reaction time, higher yields, and pure cation-anion combinations compared to the classical conventional protocol [51]. However, ILs' decomposition under sonochemical signals is a problem in this procedure. Imidazolium-based ionic liquid derivatives (1,3dibutylimidazolium-based ILs) were synthesized by Ameta, et al. using the sonochemical (ultrasound-assisted) procedure [52]. A combination of microwave and ultrasound processes was used by Leveque for the synthesis of RT ILs. This incorporation can ensure improved chemical and physical properties [53]. Fang, et al. developed a synthesis type, consisting of flexible reaction scales, so that time efficiency was ensured compared to the conventional heating synthesis [54]. The two-step process among them is the most common route to synthesize ILs, including the formation of an organic halide salt via alkylation using a haloalkane and then a metathesis reaction introducing the weakly coordinating anion [55].

Besides, the synthesis of metal nanoparticles in ILs was achieved by a number of methods such as chemical reduction, photochemical reduction, ultrasound reduction, electrochemical reduction, gas-phase, etc. [56]. Thus, ILs gain enhanced properties with metal modification. Additionally, polymerized ionic liquids with various structures have been synthesized by direct polymerization of ionic liquid monomers or through postmodification of precursor polymers such as conventional free radical polymerization, versible-deactivation radical polymerization, etc. [57].

In the related literature, there are a number of classifications of ILs depending on their different properties, anion/cation-based type, acidic/basic type, synthesis type, catalysis performance, chemical reaction procedures, etc. [58]. The most interesting aspect about the classification is that protic ILs, aprotic ILs task-specific ILs, polarizable ILs, bio-ILs, chiral ILs, metal-containing ILs, etc. depend on the generation of ILs. In order to obtain these high-quality ILs, purification is a necessary step in the overall synthesis process because a small amount of impurities have great impacts on the physicoelectro-chemical properties (diffusion, viscosity, thermal stability, melting point, dielectric constant, etc.), thereby performance of IL in implemented technology. For example, halide impurities cause a decrease in the thermal stability and stability of the inter-ionic network as well as electrochemical window. Although many studies are provided in the literature, the analytical protocols about the purification are still complicated. Before the synthesis, starting materials must be highly non-contaminant. Additionally, IL preparation must be completed in a short while to minimize impurities such as volatiles, alkylating agents, inorganic halides, protic impurities, organic amines, water, etc. [59]. The most common impurities in ILs are halide ions such as fluoride, chloride, bromide, and iodide. The main reason for their existence is unreacted starting materials and unexpected product reactions or/and side reactions in low probability [60]. Although there is no proper method to obtain halidefree ILs, multiple washing steps (prevent to crystallization of halide salts) and drying are generally preferred under high vacuum conditions. In addition, reversed-phase liquid chromatography, ion pair chromatography, hydrophilic interaction chromatography, capillary electrophoresis and ion chromatography were used to obtain halide-free IL. Transformation of imidazolium- 


\section{Nanomedicine \& Nanotechnology Open Access}

based zwitterions is another way. Synthesis of some halide-free ILs are more difficult than that of other ILs due to their miscibility with water [61]. In the halide-free purification of ILs, generally activated charcoal is used in the last step of IL synthesis [62]. However, Srivastava showed that activated charcoal was not suitable for iodide-based imidazolium IL purification [63]. Petrovic used rotary evaporation followed by vacuum method to purify $\left[\mathrm{C}_{4} \mathrm{mim}\right][\mathrm{Sal}],\left[\mathrm{HOC}_{3} \mathrm{mim}\right][\mathrm{Sal}],\left[\mathrm{HOC}_{3} \mathrm{mim}\right][\mathrm{Cl}]$ and [ $\left.\mathrm{HOC}_{2} \mathrm{OC}_{2} \mathrm{mim}\right][\mathrm{Sal}]$ [64]. Distillation and zone melting techniques have been used for the purification of protic ionic liquids and $\left.\left[\mathrm{C}_{2} \mathrm{mim}\right][\mathrm{OTf}], \quad\left[\mathrm{C}_{2} \mathrm{mim}\right] \mathrm{NTf}_{2}\right]$, respectively [65]. Sorbent materials such as activated carbon, alumina, and silica (water as a solvent) are widely used to remove organic and/or colored impurities from ILs. The sorbents require a preparation process before ILs are purified. Francesco, et al. reported that 5\% residual impurities were detected in RT IL purification [66]. High viscosity of ILs may cause a decrease in the velocity of purification as reported by Gnahm [67]. During the quaternization reaction process, the oxygen in air could result in the occurrence of colored compounds, thus the quaternization reactions should be carried out in an inert atmosphere [68]. The use of grease, silica, carbon, and alox is known to cause increased impurities.

The most interesting property of ILs is anion or cation that can be tailored depending on the specific application. Such ILs are described as 'task-specific IL' or 'functionalized IL'. A number of interesting reviews about the functionalized ILs have appeared dealing with their specific applications [69,70]. Functionalized ILs have certain desired chemical, physical, or biological properties. Functional groups, namely $-\mathrm{OH},-\mathrm{OR},-\mathrm{SH}, \mathrm{NH}_{2},-\mathrm{PPh}_{2}$, $\mathrm{Si}(\mathrm{OR})_{3}, \mathrm{SO}_{3} \mathrm{H}$, urea, or metal complex, are generally tethered covalently to anion or/and cation or zwitterion. The usual method of functionalized ILs is shown in Figure 3.

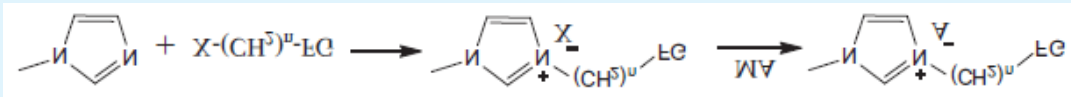

Figure 3: General synthesis route of functionalized ILs where FG: $-\mathrm{OH},-\mathrm{OR},-\mathrm{SH}, \mathrm{NH}_{2},-\mathrm{PPh}_{2},-\mathrm{Si}\left(\mathrm{OR}_{3}, \mathrm{SO}_{3} \mathrm{H}, \mathrm{urea}\right.$ or metal complex. Reprinted with permission from H. Olivier-Bourbigou, et al. [71].

Functionalized ILs with the functional group on the cation have attracted considerable attention since the compounds may easily turn into cations and carbon side chains in IL cations such as guanidinium-based ILs, hydroxyl ammonium-based ILs, imidazolium/pyridiniumbased ILs, quaternary ammonium-based ILs, phosphonium-based ILs. Cation-based functionalized ILs have been synthesized by quaternization reaction, Michael-type reaction, ILs containing both amino and carboxy groups, which can be obtained starting from amino acids or amines etc. [72]. Gao, et al. reported that the cation was designed by introducing the functionalized group of $-\mathrm{SO}_{3} \mathrm{H}$ to the cation of the IL, so a salt of $\mathrm{N}, \mathrm{N}, \mathrm{N}-$ trimethyl butylsulphonate ammonium hydrosulfate was designed [73]. Yonenaga, et al. reported that tetrapropylammonium and tetrabutylammonium cationbased ILs exhibited significant amphiphilic characteristics with strong hydrophobic and equally strong hydrophilic contributions with the use of the 1-propanol probing methodology [74]. Fujiwara, et al. synthesized ILs including imidazolium, ammonium, and phosphonium cations with aromatic amino acid anions [75].

Anion-based functionalized ILs are used especially in $\mathrm{CO}_{2}$ and $\mathrm{SO}_{2}$ capture applications. Gurkan, et al. synthesized amino acid-based ILs, including trihexyl(tetradecyl)phosphonium prolinate ([P $\left.\mathrm{P}_{66614}\right]$ [Pro]) and methioninate $\left(\left[\mathrm{P}_{66614}\right][\mathrm{Met}][76]\right.$. Che, et al. prepared fluorescent IL [P $\left.\mathrm{P}_{6614}\right][\mathrm{HBO}]$ by using the acid-base neutralization between 2-(20hydroxyphenyl)benzoxazole and a solution of phosphonium hydroxide in ethanol that was obtained from trihexyl(tetradecyl)phosphonium bromide by using the anion-exchange method [77]. Cui, et al. designed several kinds of acylamido-based anion-functionalized ILs [78]. Montano, et al. synthesized modified sodium montmorillonite with nine different methylimidazoliumbased ionic liquids and each 1-alkyl-3methylimidazolium cation was moreover modified with $\mathrm{HO}^{-}, \mathrm{Br}^{-}$and $\mathrm{BF}_{4}^{-}$anions [79]. Lethesh, et al. showed that nitrile functionalized ILs with thermal stability, especially triflate and trifluoro acetate anion containing ILs, are promising solvents for the dissolution of biomass [80].

Synthesis procedure of functionalized IL is crucial to achieve pure, cost-efficient, and sustainable functionalized ILs. Muthyala, et al. synthesized functionalized ILs by using solid-phase synthesis and fluorous phase synthesis [81]. In the esterification, ricinoleic acid [RA] with methanol was used to synthesize 


\section{Nanomedicine \& Nanotechnology Open Access}

six different functional ILs as received by Sun, et al. [82] $\mathrm{Fu}$, et al. designed alkoxysilyl-functionalized ionic liquid by ultrasonic/microwave synergistic method [83] Alamdari used anion exchange of IL-Br salt for synthesis diacidic hydroxyl functionalized ionic liquid to be used in the synthesis of diester plasticizers [84]. Turgis, et al. synthesized various functionalized hydrophobic ionic liquids based on piperidium, imidazolium, or pyridinium cations bearing ketone moieties which have been synthesized for the liquid/liquid extraction of $\mathrm{Ta}(\mathrm{V})$ [85].

Furthermore, the first dysfunctional RT ILs from the 1,2-bis(chlorosulfonyl)tetrafluoroethane were reported in 1998, another example with direct methylation of imidazole using methylated dysfunctional or tetrafunctional perfluorosulfonyl as received by Hickman [86].

Understanding ILs' properties is important to determine their purity and efficiency/stability in the application field. Molecular organization and/or dynamics of ILs as a function of the cation and anion nature and interactions between other molecule groups or metal complexes have been determined by proper analysis techniques [87].

\section{Basic analysis types of ILs for the characterization are listed below:}

-NMR: Nuclear magnetic resonance spectroscopy (NMR) is a useful method for a basic understanding of IL interactions and their supramolecular liquid structures. Based upon the earlier IL NMR studies, many ILs have an ordered internal structure in the liquid phase. The most common types of NMR are ${ }^{1} \mathrm{H}-\mathrm{NMR}$ and ${ }^{13} \mathrm{C}-\mathrm{NMR}$ in the synthetic chemistry using ILs. ${ }^{1} \mathrm{H}-\mathrm{NMR}$ and ${ }^{13} \mathrm{C}-\mathrm{NMR}$ indicated notable differences in the chemical shifts depending on the used anion. The most efficient method is ${ }^{1} \mathrm{H}-\mathrm{NMR}$ to detect the reagents and the resulting ionic liquid with a quaternization reaction. However, monitoring metathesis reactions with it is difficult because only the anion is changed. Therefore, the combination of MS(ESI) and ${ }^{1} \mathrm{H}-\mathrm{NMR}$ analysis are conductible to monitor both the quaternization and the metathesis reaction [88].

-TGA and DSC: The thermal stability of ILs and its upper temperature limit are characterized by thermal decomposition temperature (Tonset) (clough). Glass transition and Tonset of the ILs are determined by thermo gravimetric analysis (TGA) method. The thermal stability of ILs mainly depends on the ILs' natures such as cation or anion type, yet anion type is more important because decomposition temperature could rise from 200 to $400{ }^{\circ} \mathrm{C}$ with the changing anion type [89]. Thermal conductivity is measured by thermal conductivity analyzer at different temperatures. Melting points are measured with DSC or a different melting point apparatus, but it is not reliable due to the supercooling condition [vadapalli]. The melting point of ILs with unsymmetrical cations and a delocalized charge depends on the hydrogen-bonding presence, packing efficiency, and cation/anion composition [90].

-SEM: IL droplet gives a dark contrast scanning electron microscope (SEM) images because the ILs are not charged by electron beam irradiation without any noise until the applied highly accelerated voltage. Clear ILs images have been obtained by low accelerated voltage under $1 \mathrm{kV}$ to solvate electrons and allow them to move in the liquid. With their liquid form and low vapor pressure, ILs can be directly observed by SEM [91]. Several attempts have been made for SEM observations using IL treatment especially in biological and medical studies. Because biological specimens have complex surface structures, metal or carbon deposition cannot perfectly deposit conducting films on the surfaces [92].

-XRD: In general, X-Ray diffraction can be used to determine solid (crystal) structure and to obtain data about the "liquid" structure. The structure factors and the radial distribution functions can be obtained from diffraction patterns as a fingerprint of the ionic liquid. This method is especially useful when thin film is intercalated with ionic liquid materials [93].

-XPS: X-ray photoelectron spectroscopy (XPS) is a useful method to allow for the detection of species dissolved in the IL, enabling in situ analysis of chemical reactions. Depending on the change in electronic environment of a certain element present in ionic liquids and the cationanion interaction in ionic liquids, the surface composition of ionic liquids is determined by XPS [94].

-CV: Cyclic voltammetry (CV) is a tool to investigate electrochemical properties and also to determine diffusion coefficients of ILs as an electrolyte in the electrochemical cells such as batteries, fuel cells, thermoelectrochemical cells. In general, it has been performed by using three electrode cells (counter electrode, working electrode, and pseudo-reference) with non-isothermal cells. AC impedance spectroscopy is used to evaluate the conductivity of solvents with it.

\section{Thermoelectrochemical Applications of Ionic Liquids}

Thanks to tremendous demand for renewable energy sources and because of increasing pollution, growing 


\section{Nanomedicine \& Nanotechnology Open Access}

human population, and greenhouse effect, thermal energy devices significantly contribute to sustainable energy technology. Nearly $63 \%$ of global energy consumption occurs due to waste heat [95]. As an alternative energy generation, thermoelectrochemistry studies deal with this waste thermal energy to reconvert it into useful electricity. Harvesting thermal energy has wide accessibility and abundance such as heat body, power station waste heat, geothermal activities, car dashboard, industrial waste streams, etc. Thermal energy converting methods may be categorized as thermoelectrics, thermocouples, and stirling engines and thermoelectrohemical cells.

Thermoelectrochemical cells (TECs), sometimes called thermogalvanic or thermocells, are interesting to research due to the waste heat/electricity conversion (conversion of temperature gradient to reliable electrical voltage) as an alternative to traditional energy conversion devices. No emissions and consuming materials are produced; rather, direct and continious conversion are observed.

TECs rely upon an entropy difference between the two electrodes, where dissimilar temperature sides with a redox reaction, so a potential difference can be generated across two electrodes accompanying proportional to the temperature difference. One electrolyte is located between and contact two electrodes on both sides. The thermoelectric (open circuit) voltage is directly linked to the temperature dependence of the redox potential. Increased temperature difference between the two electrodes causes an increased output of cell voltage. The resulting temperature-dependent potential difference is typically summarized as the Seebeck coefficient (Se) as shown by Equation (4).

$$
\mathrm{Se}=\Delta \mathrm{E} / \Delta \mathrm{T}(\mathbf{4})
$$

where $\mathrm{E}$ is the potential and $\mathrm{T}$ is the temperature. Standard high Se is around $\mathrm{mVK}^{-1}$ and the negative sign indicates that the hot electrode behaves as the anode [96]. When equation (4) is modified according to thermodynamical rules, electrochemical thermopower of thermocell can be given by equation (5);

$$
\mathrm{SE}=\partial \mathrm{E} / \partial \mathrm{T}=-\Delta \mathrm{S} / \mathrm{nF}(\mathbf{5})
$$

where $\mathrm{E}$ is full-cell voltage, $\mathrm{T}$ is temperature, $\mathrm{n}$ is the number of electrons transferred in the reaction, $\mathrm{F}$ is Faraday's constant and $\Delta \mathrm{S}$ is the entropy change for the cell reaction under the standard condition.
In an ideal TEC, the small temperature difference in waste heat between the heat source, and the surrounding ambient equal a high electric voltage. The main purpose is to achieve high power density output and conversion efficiency; therefore, cell design must be improved and optimized with electrode materials and electrolyte materials and by redox process through oxidation and reduction reactions and adjustment of the quantity and mobility of the redox couples, etc. The responsibility of electrolytes is ion transfer between anode and cathode during charge-discharge processes depending on the charge transport and diffusion capability of ions.

There are a great number of studies having investigated dissolving redox couples in a suitable solvent or electrolyte. The most common aqueous thermocells contains generally $0.4 \mathrm{M}$. ferrocenium/ferrocene $\left(\left[\mathrm{Fe}(\mathrm{CN})_{6}\right]^{3-} /\left[\mathrm{Fe}(\mathrm{CN})_{6}\right]^{4-}\right)$ due to the highest Seebeck coefficient $\left(1.4 \mathrm{mV} \mathrm{K}^{-1}\right)$, where ferrocene solubility is rather low. This value ranges between $1 \mathrm{mVK}^{-1}$ and 1.7 $\mathrm{mVK}^{-1}$ for dissolution in water and depends on the supporting electrolytes that have high boiling temperatures such as DMSO, g-butyrolactone, DMF and IL and spin state changes [97]. ILs are very suitable with their low vapor pressure, which allows for longer service lifetimes and chemical stability, which allows for the harvest of higher-temperature waste heat. Cobalt, iodine, iron, nickel and sulfur-based redox couples in ionic liquids are being increasingly investigated [98]. Functionalized ILs can be used to increase solubility of redox-active compounds. Han, et al. tethered ferrocene and quaternary ammonium or phosphonium cations and these IL salts showed soluble and non-volatile properties [99].

Besides, solid state TECs are the first examined membranes and also typically semiconductors and their working principles based on Seebeck effect, its 2Dschematical representation are shown in Figure 4. Compared to solid-state TECs, liquid types involving various redox couples in solutions are preferred in the practical applications because solid-state TECs have low Seebeck coefficient $\left(S_{e}\right)(\mu V / K)$, high preparation costs, relatively low efficieny and long-term production. In liquid-based TECs, the solutions may be aqueous (e.g. containing the ferrocyanide/ ferricyanide redox couple), organic (3-methoxypropionitrile (MPN)), gelled (agar agar) or ionic liquid [100]. Aqueous-based electrolytes restrict their operating temperatures to less than $100{ }^{\circ} \mathrm{C}$ due to the parasitic heat transport and they have limited electrochemical window less than $\sim 1 \mathrm{~V}$, so device performance decreases. 


\section{Nanomedicine \& Nanotechnology Open Access}

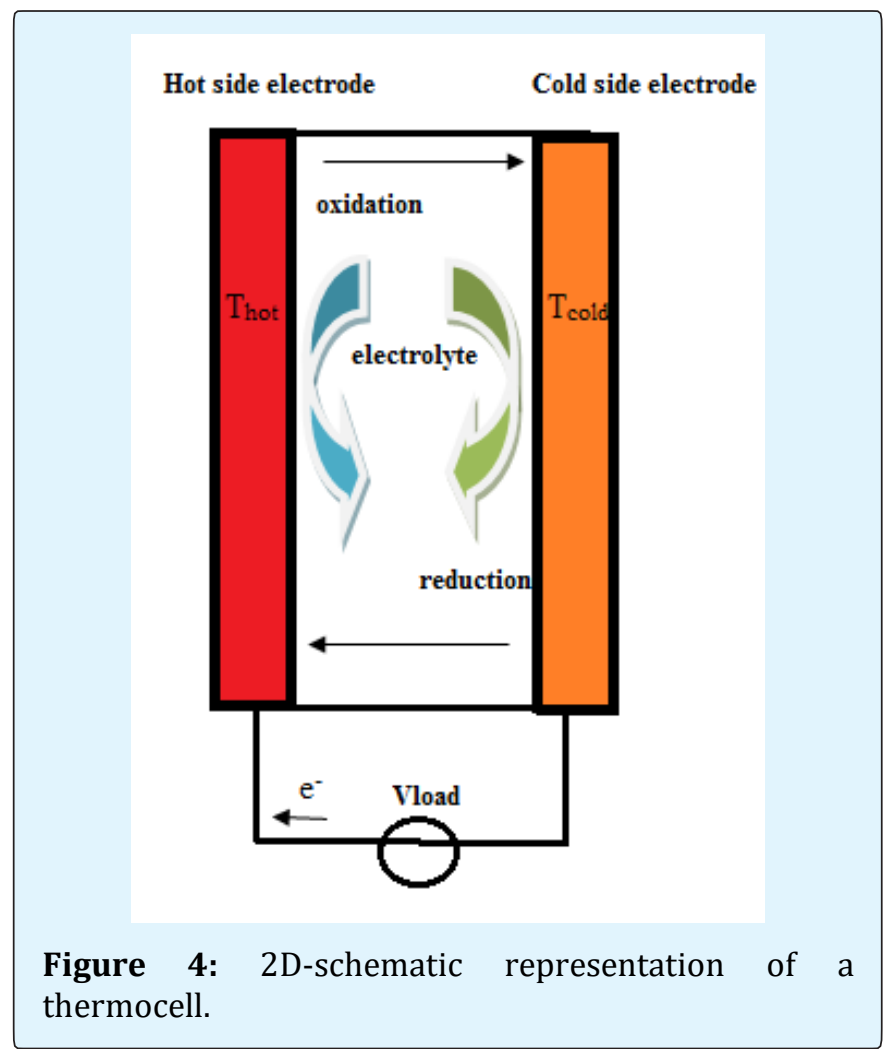

ILs are new alternative materials as solvents or electrolytes in energy technology with their incredible properties. Energy technology device types may be subcategorized as advanced batteries (e.g. lithium batteries, sodium ion cells, magnesium batteries), dyesensitized solar cells, double layer capacitors, actuators, fuel cells, hydrogen storage systems, and thermo-cells. Common IL ion families using energy applications are described by Macfarlane, et al. in Figure 5.

As an electrolyte, ILs are attractive thanks to their good thermal and electrochemical stability, high ionic conductivity, very high electrochemical window of $\sim 3-4 \mathrm{~V}$, non-volatility, and non-flammability properties [101]. In the mid- to high-temperature range, the operating temperature of ILs (up to $\sim 300^{\circ} \mathrm{C}$ ) is higher than aqueous and organic solutions particularly, so they are suitable solutions to harvest in thermal energy applications. Additionally, low thermal conductivity allows a larger temperature difference to be maintained across the cell. Seebeck coefficient is directly related to the structural changes of the redox species and the solvent during the redox reaction. Wide liquid temperature range of ILs allows high voltage due to the larger temperature differences between the two electrodes. At this point, ILs' influence on the redox couples must be understood so can obtain higher Seebeck coefficients.

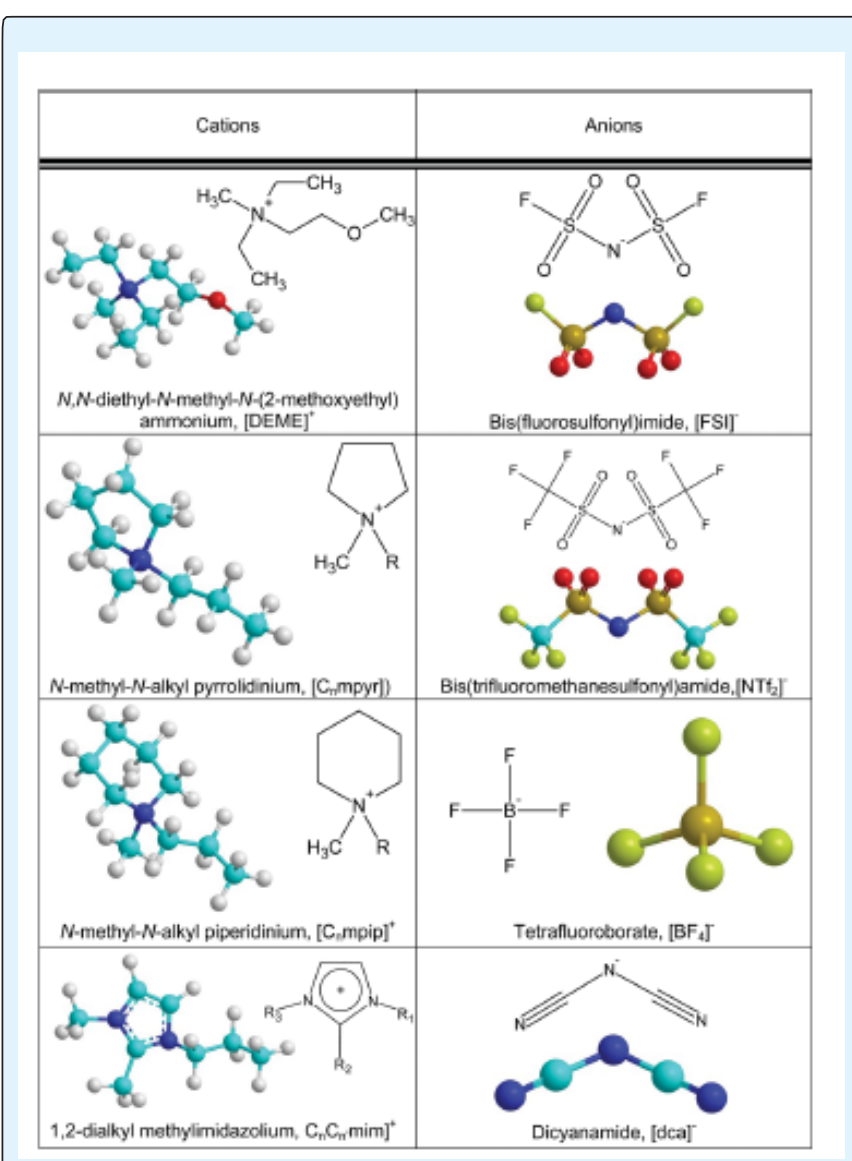

Figure 5: Common ionic liquid families to use energy applications, reprinted with permission from D. R. MacFarlane, et al. [101].

In 1968, for the first time Cornwell, et al. showed the use of ILs in TECs, but the ILs' effects were not fully understood [102]. In 1980, Chum, et al. contributed with a similar study [103].

The first reported functioning TEC with an ionic liquid was produced by Abraham, et al. [104]. As an electrolyte, The $\left[\mathrm{Fe}(\mathrm{CN})_{6}\right]^{3-} /\left[\mathrm{Fe}(\mathrm{CN})_{6}\right]^{4-}$ redox couple in choline $\left[\mathrm{H}_{2} \mathrm{PO}_{4}\right]$ combined with water and single-walled carbon nanotubes (SWNTs) as an hot-cold electrodes were used. In another study conducted by Abraham, IL electrolyte was achieved using $\mathrm{Co}^{\mathrm{II} / \mathrm{III}}$ tris(bipyridyl) redox couple in 1-ethyl-3methylimidazolium tetracyanoborate IL that showed the highest power density $\left(240 \mathrm{~W} \mathrm{~m}^{-2}\right)$ [105]. Aldous, et al. investigated that the ferrocenium|ferrocene redox couple in an ionic liquid and redox centre had been covalently 


\section{Nanomedicine \& Nanotechnology Open Access}

tethered to either the 1-ethyl-3(methylferrocenyl)imidazolium[EimFc]+ cation or ferrocenylsulfonyl (trifluoro-methylsulfonyl)imide anion, $\left[\mathrm{FcNT}_{\mathrm{f}}\right]$. It was showed that tethering a fixed charge to a desirable redox centre could simultaneously improve solubility and entropic changes [106]. Black, et al. showed that lithium bis(trifluoromethylsulfonyl)imide $\left(\mathrm{Li}\left[\mathrm{NTf}_{2}\right]\right) /$ tetraglyme(G4) mixing resulted in thermoelectrochemical electrolytes when combined with lithium metal electrodes [107]. $S_{\mathrm{e}}$ results of the $\mathrm{I}^{-} / \mathrm{I}^{3-}$ redox couple in ILs for TEC were found to be $0.03,0.26$, and $1.67 \mathrm{mV} \mathrm{K}^{-1}$ corresponding to $\left[\mathrm{P}_{2,2,2,(101)}\right]\left[\mathrm{NTf}_{2}\right], \quad\left[\mathrm{C}_{2} \mathrm{mim}\right]\left[\mathrm{BF}_{4}\right]$ and $\left[\mathrm{C}_{2}\right.$ mim] [NTf 2 , respectively [108].

Cabral, et al. investigated that electrochemistry of redox couple $\left(\left[\mathrm{Co}(\mathrm{bpy})_{3}\right]^{2+/ 3+}\right.$ ) in four types of ILs and three aprotic molecular solvents. The diffusion coefficient of $\left[\mathrm{Co}(\mathrm{bpy})_{3}\right]^{2+}$ was related to solvent viscosity and the $\mathrm{k}^{0}$ values of $\left[\mathrm{Co}(\mathrm{bpy})_{3}\right]^{2+/ 3+}$ in the ILs were high on GC working electrode. The $\left[\mathrm{Co}(\mathrm{bpy})_{3}\right]^{1+/ 2+}$ reaction was not chemically reversible in 3-methoxypropionitrile [109].

The $\left[\mathrm{Co}^{\mathrm{II} / \mathrm{III}}(\mathrm{bpy})_{3}\right]\left(\mathrm{NTf}_{2) 2 / 3}\right.$ redox couple in a range of different ionic liquids was investigated by $\mathrm{He}$, et al. to determine ILs' effects on the thermodynamic properties and they showed that addition of propylene carbonate to the ILs significantly caused an increase in the current and power densities. In this comprehensive study, the selected ILs were (1-butyl-3-methylimidazolium bis(trifuoromethanesulfonyl)imide, $\quad\left[\mathrm{C}_{4} \mathrm{mim}\right]\left[\mathrm{NTf}_{2}\right], \quad 1$ butyl-2,3-dimethylimidazolium

bis(trifuoromethanesulfonyl)imide, $\left[\mathrm{C}_{4} \mathrm{dmim}\right]\left[\mathrm{NTf}_{2}\right], \quad 1-$ butyl-2,3-dimethylimidazolium trifuoromethanesulfonate, [ $\left.\mathrm{C}_{4} \mathrm{dmim}\right][\mathrm{OTf}], \quad 1$-butyl-3- methylimidazolium tetrafuoroborate, $\quad\left[\mathrm{C}_{4} \mathrm{mim}\right]\left[\mathrm{BF}_{4}\right], \quad$ 1-butyl-3methylimidazolium methanesulfonate, $\left[\mathrm{C}_{4} \mathrm{mim}\right]\left[\mathrm{MeSO}_{3}\right]$, 1-ethyl-3-methylimidazolium methanesulfonate, [ $\left.\mathrm{C}_{2} \mathrm{mim}\right]\left[\mathrm{MeSO}_{3}\right], \quad$ 1-butyl-3-methylimidazolium tris(pentafuoroethyl)trifuorophosphate $\left[\mathrm{C}_{4} \mathrm{mim}\right][\mathrm{eFAP}]$, trihexyl(tetradecyl)phosphonium

bis(trifuoromethanesulfonyl)imide, $\quad\left[\mathrm{P}_{6,6,6,14}\right]\left[\mathrm{NTf}_{2}\right]$, trihexyl(tetradecyl)phosphonium p-toluenesulfonate,

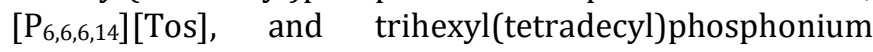
tetrafuoroborate, $\left[\mathrm{P}_{6,6,6,14}\right]\left[\mathrm{BF}_{4}\right]$.

In a study by Anari in 2016, the thermoelectrochemistry of mixed redox couples (ferrocene and iodine) were investigated for the first time and the value of $1.67 \mathrm{mV} \mathrm{K}^{-1}$ for [DiBoylFc][ $\mathrm{I}_{3}$ ] being one of the highest reported Seebeck coefficient for a solute in the ionic liquid [Emim] $\left[\mathrm{NTf}_{2}\right]$. Siddique, et al. received that the power and current output density of $\mathrm{I}^{-} / \mathrm{I}^{3-}$ redox couple in ammonium-based protic ILs for TEC and the highest reported Se value was $420 \mathrm{mV} \mathrm{K}^{-1}$ for $\mathrm{I}^{-} / \mathrm{I}^{3-}$ redox process. These protic ILs were Bis(2ethylhexyl)ammonium trifuoroacetate (BEHA TFA), Bis(2-ethylhexyl) ammonium methanesulfonate (BEHA MS), Bis(2-ethylhexyl)ammonium trifuoromethanesulfonate (BEHA TFMS), Bis(2ethylhexyl)ammonium tosylate (BEHA tosylate), Tris(2ethylhexyl)ammonium trifuoroacetate (TEHA TFA), Tris(2-ethylhexyl) ammonium methanesulfonate (TEHA MS), Tris(2-ethylhexyl)ammonium trifuoromethanesulfonate (TEHA TFMS), and Tris(2ethylhexyl)ammonium tosylate [110].

Anion or cation intercalation-based energy storage systems have been investigated by many researchers [111]. As electrode material using graphite with a combined non-aqueous electrolyte was first developed by Carlin, et al. They adapted the reductive and oxidative intercalation from ionic liquid electrolytes without any additional salt such as 1-ethyl-3- methylimidazolium hexafluorophosphate $\left(\mathrm{EMI}^{+} \mathrm{PF}_{6}^{-}\right)$[112]. Lastly, in the study by Agiorgousis, Al-graphite electrochemical cell involving IL as an electrolyte was detected to have high voltage due to the thermodynamic instability of the $\mathrm{AlCl}_{4}{ }^{-}$ intercalated graphite [113]. Before this, a similar study was reported by Choi on the destructive intercalation of MMDMEA cations that contributed to the enhancement of cycling performance in graphite $/ \mathrm{LiCoO}_{2}$ cells with DMC/MMDMEA-TFSI/1 M LiPF 6 in Li-ion battery [114]. The ability to perform similar experimental studies in TECs can lead to the achievement of successful results.

A more detailed electrochemical model involving IL as an electrolyte is needed for future studies and the influence of the nature of cation or anion of IL on the TECs performance is not yet well understood, especially in relation to functionalized ILs.

\section{Conclusion}

Until today, a great number of scientific papers and books with ionic liquids (ILs) have been reported. Undoubtedly, their desirable and functional properties have increased the interest in them. Due to the wide application areas of ILs and many IL synthesis processes for this purpose, IL is a comprehensive research field that needs to be investigated from various perspectives.

The increase in people's demand for sustainable technology devices leads to the introduction of such applications to everyday life. Of them, thermoelectrochemical cells (TECs) are very important as alternative and cheap renewable energy devices. Recently, 


\section{Nanomedicine \& Nanotechnology Open Access}

development and research activities concerning this topic have increased.

Electrolyte type and electrolyte/electrode interaction play important roles in electrochemical cells. Especially over the last years, ILs as an electrolyte have been shown to enhance performance in the electrochemical cells (batteries, actuators, fuel cells, thermoelectrochemical cells) that were widely adapted to our lifestyle. ILs transform into liquid form over a wider temperature range, which offers advantages for the electrochemical devices.

In this chapter, we have introduced some useful reviews about ILs, especially as an electrolyte in TECs. Additionally, it is also planned to lay the groundwork for similar future studies on functionalized ILs, recovery of the redox couple, electrode material and various IL electrolytes and the use of redox couples in ionic liquid (IL) electrolytes.

\section{References}

1. Hurley HF (1948) patent nr 4446331, US; Wier TP Jr, Hurley FH (1948) patent 4446349, US; Wier TP Jr (1948) patent 4446350, US.

2. Watanabe M, Thomas ML, Zhang S, Ueno K, Yasuda T, et al. (2017) Application of Ionic Liquids to Energy Storage and Conversion Materials and Devices. Chem Rev 117(10): 7190-7239.

3. Zentel T, Overbeck V, Michalik D, K"uhn O, Ludwig R (2018) Hydrogen bonding in protic ionic liquids: structural correlations, vibrational spectroscopy, and rotational dynamics of liquid ethylammonium nitrate. J Phys B at Mol Phys 51(3): 034002-034012.

4. Mai NL, Ahn K, Koo Y (2014) Methods for recovery of ionic liquids-A review. Process Biochemistry 49(5): 872-881.

5. Gadilohar BL, Shankarling GS (2017) Choline based ionic liquids and their applications in organic transformation. Journal of Molecular Liquids 227: 234-261.

6. Vekariya RL (2017) A review of ionic liquids: Applications towards catalytic organic transformations. Journal of Molecular Liquids 227: 44-60.
7. Mehrkesh A, Karunanithi AT (2016) Life Cycle Perspectives on Human Health Impacts of Ionic Liquids. Bio R xiv.

8. Mehdi H, Binnemans K, Van Hecke K, Van Meervelt L, Nockemann P (2010) Hydrophobic ionic liquids with strongly coordinating anions. Chem Commun 46(2): 234-236.

9. Bhatt I, May I, Volkovich VA, Collison D, Helliwell M, et al. (2005) Structural Characterization of a Lanthanum Bistriflimide Complex, $\mathrm{La}\left(\mathrm{N}_{(}\left(\mathrm{SO}_{2} \mathrm{CF}_{3}\right)_{2}\right) 3\left(\mathrm{H}_{2} \mathrm{O}\right)_{3}$, and an Investigation of $\mathrm{La}, \mathrm{Sm}$, and Eu Electrochemistry in a Room-Temperature Ionic Liquid, $\left[\mathrm{Me}_{3} \mathrm{NnBu}\right]\left[\mathrm{N}\left(\mathrm{SO}_{2} \mathrm{CF}_{3}\right)_{2}\right]$. Inorg Chem 44(14): 49344940.

10. Hayakawa EH, Mochizuki E, Tsuda T, Akiyoshi K, Matsuoka H, et al. (2013) The Effect of Hydrophilic Ionic Liquids 1-Ethyl-3-Methylimidazolium Lactate and Choline Lactate on Lipid Vesicle Fusion. Plos One 8(12): 85467-85476.

11. Jiao F, Gao F, Wang H, Deng Y, Zhang Y, et al. (2017) Nature 6984: 11.

12. Amarasekara AS (2016) Acidic Ionic Liquids. Chem Rev 116(10): 6133-6183.

13. Hajipoura AR, Rafiee F (2009) Basic ionic liquids. A short review. J Iran Chem Soc 6(4): 647-678.

14. Li a Z, Wei Q, Yuan R, Zhou X, Liu H, et al. (2007) A new room temperature ionic liquid 1-butyl-3trimethylsilylimidazolium hexafluorophosphate as a solvent for extraction and preconcentration of mercury with determination by cold vapor atomic absorption spectrometry. Talanta 71(1): 68-72.

15. Kimble C, Burba CM (2017) Liquid Structure of Bis (trifluoromethylsulfonyl) imide-Based Ionic Liquids Assessed by FT-IR Spectroscopy. J Phys Chem B 121(14): 3099-3110.

16. Pernak J, Rzemıenıeckı T, Materna K (2016) Ionic liquids „in a nutshell” (history, properties and development). CHEMIK 70(9): 471-480.

17. Shamsuri A, Abdullah DK (2010) Ionic Liquids: Preparations and Limitations. MAKARA SAINS 14(2): 101-106.

18. Shukla M, Saha S (2013) A Comparative Study of Piperidinium and Imidazolium Based Ionic Liquids: Thermal, Spectroscopic and Theoretical Studies. In: 


\section{Nanomedicine \& Nanotechnology Open Access}

Jun-ichi Kadokawa (Eds.), ionic-liquids-New Aspects for the Future, Intechopen.

19. Pena-Pereira F, Namies'nik J (2014) Ionic Liquids and Deep Eutectic Mixtures: Sustainable Solvents for Extraction Processes. Chemsuschem 7(7): 1784-1800.

20. Karuppasamy K, Kim H, Kim D, Vikraman D, Prasanna $\mathrm{K}$, et al. (2017) An enhanced electrochemical and cycling properties of novel boronic Ionic liquid based ternary gel polymer electrolytes for rechargeable $\mathrm{Li} / \mathrm{LiCoO}_{2}$ cells. Sci Rep 7(1): 11103-11114.

21. Kärkkäınen J (2007) Preparatıon and Characterization of Some Ionic Liquids and Their Use in the Dimerization Reaction of 2-Methylpropene, the Faculty of Science of the University of Oulu.

22. Ghandi K (2014) A Review of Ionic Liquids, Their Limits and Applications. Green and Sustainable Chemistry 4(1): 44-53.

23. Liwarska-Bizukojc E, Maton C, Stevens CV (2015) Biodegradation of imidazolium ionic liquids by activated sludge microorganisms. Biodegradation 26(6): 453-463.

24. Oliveira MVS, Vidal BT, Melo CM, R de CM de Miranda, Soares CMF, et al. (2016) (Eco) toxicity and biodegradability of protic ionic liquids. Chemosphere 147: 460-466.

25. Mutabil MIA, Ghanem OB (2017) Ecotoxicity of Ionic Liquids towards Vibrio fischeri: Experimental and QSAR Studies. In: Scott Handy (Eds.), Progress and Developments in Ionic Liquids chapter 18. Intec Open.

26. Bubalo MC, Radošević K, Redovniković IR, Slivac I, Srček VG (2017) Toxicity mechanisms of ionic liquids. Arh Hig Rada Toksikol 68: 171-179.

27. Soheilmoghaddam M, Adelnia H, Sharifzadeh G, Wahit MU, Wong TW, et al. (2017) Bionanocomposite regenerated cellulose/single-walled carbon nanotube films prepared using ionic liquid solvent. Cellulose 24(2): 811-822.

28. Hulsbosch J, De Vos DE, Binnemans K, Ameloot $\mathrm{R}$ (2016) Biobased Ionic Liquids: Solvents for a Green Processing Industry? ACS Sustainable Chem Eng 4(6): 2917-2931.

29. Gabriel S, Weiner J (1888) Ueber einige Abkömmlinge des Propylamins. EURJIC 21(2): 2669-2679.
30. Kuchenbuch, Giernoth R (2015) Ionic Liquids beyond Simple Solvents: Glimpses at the State of the Art in Organic Chemistry. Chemistry Open 4(6): 677-681.

31. Doble M, Kruthiventi AK (2007) Green Chemistry and Processes, Elsevier.

32. Wilkes JS (2002) A short history of ionic liquidsfrom molten salts to neoteric solvents. Green Chemistry 4(2): 73-80.

33. Ozokwelu D, Zhang S, Okafor O, Cheng W, Litombe N (2017) Chapter 2 - Preparation and Characterization of Ionic Liquids. Novel Catalytic and Separation Processes Based on Ionic Liquids: 13-44.

34. Ren S, Hou Y, Zhang K, Wu W (2017) Green Energy \& Environment 1-12.

35. Deshmukh RR, Rajagopal R, Srinivasan KV (2001) Ultrasound promoted $\mathrm{C}-\mathrm{C}$ bond formation: Heck reaction at ambient conditions in room temperature ionic liquids. Chem Commun 17: 1544-1545.

36. Zhao D, Wu M, Kou Y, Min E (2002) Ionic liquids: applications in catalysis. Catal Today 74(1-2): 157189.

37. Tshemese Z, Khan MD, Mlowe S, Revaprasadu N (2018) Synthesis and characterization of $\mathrm{PbS}$ nanoparticles in an ionic liquid using single and dual source precursors. Materials Science \& Engineering B 227: 116-121.

38. Claus J, Sommer FO, Kragl U (2018) Ionic liquids in biotechnology and beyond. Solid State Ionics 314: 119-128.

39. Ren S, Hou Y, Tian S, Chen X, Wu W (2013) What Are Functional Ionic Liquids for the Absorption of Acidic Gases?. J Phys Chem B 117(8): 2482-2486.

40. Ajam M (2005) Metathesis and Hydroformylation Reactions in Ionic Liquids, the Faculty of Science of University of Johannesburg.

41. Kirchner B (2009) Ionic Liquids, Springer, 2009.

42. Liu Y, Ma C, Men S, Jin Y (2018) An investigation of trioctylmethylammonium ionic liquids by X-ray photoelectron spectroscopy: The cation-anion interaction. Journal of Electron Spectroscopy and Related Phenomena 223: 79-83. 


\section{Nanomedicine \& Nanotechnology Open Access}

43. Ferraz R, Prudêncio C, Vieira $M$, Fernandes $R$, Noronha JP, et al. (2015) Ionic Liquids SynthesisMethodologies. Organic Chem Curr Res 4(1).

44. Ratti R (2014) Ionic Liquids: Synthesis and Applications in Catalysis. Advances in Chemistry.

45. Srour H, Rouault H, Santini CC, Chauvin Y (2013) A silver and water free metathesis reaction: a route to ionic liquids. Green Chem 15(5): 1341-1347.

46. Stojanovic, Morgenbesser C, Kogelnig D, Krachler R, Keppler BK (2011) Ionic Liquids: Theory, Properties, New Approaches. In: Alexander Kokorin (Eds.), Quaternary Ammonium and Phosphonium Ionic Liquids in Chemical and Environmental Engineering chapter 26, Intechopen.

47. Depuydt D, Van den Bossche A, Dehaen W, Binnemans K (2016) Halogen-free synthesis of symmetrical 1,3dialkylimidazolium ionic liquids using non-enolisable starting materials. RSC Adv 6(11): 8848-8859.

48. Irge DD (2016) Ionic Liquids: A Review on Greener Chemistry Applications, Quality Ionic Liquid Synthesis and Economical Viability in a Chemical Processes. American Journal of Physical Chemistry 5(3): 74-79.

49. Zbancioc G, Mangalagiu II, Moldoveanu C (2015) Ultrasound assisted synthesis of imidazolium salts: An efficient way to ionic liquids. Ultrasonics Sonochemistry 23: 376-384.

50. Hakala U (2009) Ionic Liquids and Microwaves in Promotion of Organic Synthesis, University of Helsinki Faculty of Science.

51. Zang H, Su Q, Mo Y, Cheng B (2011) Ionic liquid under ultrasonic irradiation towards a facile synthesis of pyrazolone derivatives. Ultrasonics Sonochemistry 18(1): 68-72.

52. Ameta G, Pathak AK, Ameta C, Ameta R, Punjabi PB (2015) Sonochemical synthesis and characterization of imidazolium based ionic liquids: A green pathway. Journal of Molecular Liquids 211: 934-937.

53. Lévêquea J, Cravotto G (2006) Microwaves, Power Ultrasound, and Ionic Liquids. A New Synergy in Green Organic Synthesis. Chimia 60(6): 313-320.

54. Fang D, Cheng J, Gong K, Shi Q, Zhou X, et al. (2008) A green and novel procedure for the preparation of ionic liquid. Journal of Fluorine Chemistry 129(2): 108-111.
55. Rutz C, Schmolke L, Gvilava V, Janiak C (2017) Anion Analysis of Ionic Liquids and Ionic Liquid Purity Assessment by Ion Chromatography. Z Anorg Allg Chem 643(1): 130-135.

56. Janiak C (2015) Metal Nanoparticle Synthesis in Ionic Liquids. Top Organomet Chem 51: 17-54.

57. He H, Luebke D, Nulwala H, Matyjaszewski K (2014) Synthesis of Poly(ionic liquid)s by Atom Transfer Radical Polymerization with ppm of $\mathrm{Cu}$ Catalyst. Macromolecules 47(19): 6601-6609.

58. Dzyuba SV (2002) Synthesis. Properties and Applıcatıons of Ionıc Liquıds, Texas Tech University.

59. McIntosh JS, Griffith J, Gräsvik J (2016) Methods of Synthesis and Purification of Ionic Liquids, chapter 2. Application, Purification, and Recovery of Ionic Liquids 59-99.

60. Stark, Behrend P, Braun O, Muller A, Ranke J, et al. (2008) Purity specification methods for ionic liquids. Green Chem 10(11): 1152-1161.

61. Wasserscheid P, Welton T (2003) Ionic Liquids in Synthesis. OPR\&D.

62. Ozokwelu D, Zhang S, Okafor O, Cheng W, Litombe N (2017) Novel Catalytic and Separation Processes Based on Ionic Liquids chapter 2.

63. Srivastava N, Shukla M, Saha S (2010) An unusal effect of charcoal on the purification of alkylimidazolium iodide room temperature ionic liquids. Indıan Journal of Chem 49A: 757-761.

64. Trtic-Petrovic T, Dimitrijevic A, Zdolsek N, Dordevic J, Tot A, et al. (2018) New sample preparation method based on task-specific ionic liquids for extraction and determination of copper in urine and wastewater. Anal Bioanal Chem 410(1): 155-166.

65. Clare B, Sirwardana A, Macfarlane DR (2009) Synthesis, Purification and Characterization of Ionic Liquids 290: 1-40.

66. De Francesco M, Simonetti E, Gorgi G, Appetecchi GB (2017) About the Purification Route of Ionic Liquid Precursors. Challenges 8(1): 1-17.

67. Oll O, Siimenson C, Lust K, Gorbatovski G, Lus E (2017) Specific adsorption from an ionic liquid: impedance study of iodide ion adsorption from a pure halide ionic liquid at bismuth single crystal planes. Electrochimica Acta 247: 910-919. 


\section{Nanomedicine \& Nanotechnology Open Access}

68. Gnahm M, Kolb DM (2011) The purification of an ionic liquid. Journal of Electroanalytical Chemistry 651(2): 250-252.

69. Li H, Bhadury PS, Song B, Yang S (2012) Immobilized functional ionic liquids: efficient, green, and reusable catalysts. RSC Advances 2: 12525-12551.

70. Messali M (2015) Conventional versus ultrasound and microwave assisted synthesis: Some new environmentally friendly functionalized picoliniumbased ionic liquids with potential antibacterial activity. Acta Pharm 65(3): 253-270.

71. Olivier-Bourbigou H, Magna L, Morvan D (2010) Ionic liquids and catalysis: Recent progress from knowledge to applications. Applied Catalysis A: General 373(1-2): 1-56.

72. Chiappe, Pomelli CS (2014) Point-Functionalization of Ionic Liquids: An Overview of Synthesis and Applications. Eur J Org Chem 2014(28): 6120-6139.

73. Gao J, Wang G, Wang Z, Wang Y, Liu J, et al. (2014) Design and synthesis of cation-functionalized ionic liquid for application as electrolyte in proton exchange membrane fuel cells. J Mater Chem A 2(45): 19275-19281.

74. Yonenaga K, Morita T, Nishikawa K, Koga Y (2018) Effects of ionic liquid constituent cations, tetraalkylammoniums, on water studied by means of the "1-propanol probing methodology". Journal of Molecular Liquids 252: 58-61.

75. Fujiwara S, Ichikawa T, Ohno H (2016) Cation- $\pi$ interactions within aromatic amino acid ionic liquids: A new tool for designing functional ionic liquids. Journal of Molecular Liquids 222: 214-217.

76. Gurkan E, de la Fuente JC, Mindrup EM, Ficke LE, Goodrich BF, et al. (2010) Equimolar CO2 Absorption by Anion-Functionalized Ionic Liquids. J Am Chem Soc 132(7): 2116-2117.

77. Che S, Dao R, Zhang W, Lv X, Li H, et al. (2017) Designing an anion-functionalized fluorescent ionic liquid as an efficient and reversible turn-off sensor for detecting $\mathrm{SO}_{2}$. Chem Commun 53(27): 3862-3865.

78. Cui G, Zhang F, Zhou X, Huang Y, Xuan X et al. (2015) Acylamido-Based Anion-Functionalized Ionic Liquids for Efficient SO2 Capture through Multiple-Site Interactions. ACS Sustainable Chem Eng 3(9): 22642270 .
79. Montano F, Casanova H, Cardona WI, Giraldo LF (2017) Functionalization of montmorillonite with ionic liquids based on 1-alkyl-3-methylimidazolium: Effect of anion and length chain. Materials Chemistry and Physics 198: 386-392.

80. Lethesh KC, Shahb SN, Ayodele OB, Abdul Mutalib MI, Uemura Y (2016) Nitrile-functionalized azepanium ionic liquids: Synthesis characterization and thermophysical properties. Journal of Molecular Liquids 221: 1140-1144.

81. Muthyala MK, Velisetti K, Parang K, Kumar A (2014) Advances in Functionalized Ionic Liquids as Reagents and Scavengers in Organic Synthesis. Current Org Chem 18(19): 2530-2554.

82. Sun S, Li X (2016) Functional Ionic Liquids Catalyzed the Esterification of Ricinoleic Acid with Methanol to Prepare Biodiesel: Optimization by Response Surface Methodology. J Am Oil Chem Soc 93(6): 757-764.

83. Fu XQ, Sheng X, Zhou Y, Fu Z, Zhao S, et al. (2016) One-step synthesis of hierarchical aluminosilicates using alkoxy-functionalized ionic liquid as a novel template. New J Chem 40(7): 6036-6045.

84. Fareghi-Alamdari R, Niri MN, Hazarkhan H (2017) Synthesis and characterization of a new hydroxyl functionalized diacidic ionic liquid as catalyst for the preparation of diester plasticizers. Journal of Molecular Liquids 227: 153-160.

85. Turgis R, Arrachart G, Dubois V, Dourdain S, Virieux $D$, et al. (2016) Performances and mechanistic investigations of a triphosphine trioxide/ionic liquid system for rare earth extraction. Dalton Trans 45(3): 1259-1268.

86. Hickman T, Des Marteau DD (2012) Synthesis of 1,3dialkyl imidazolium ionic liquids containing difunctional and tetrafunctional perfluoroalkylsulfonyl imide anions. Journal of Fluorine Chemistry 133: 11-15.

87. Feder-Kubis J (2011) NMR spectroscopy in studies of new chiral ionic liquids. Polymery 56(9): 676-681.

88. Cao Y, Mu T (2014) Comprehensive Investigation on the Thermal Stability of 66 Ionic Liquids by Thermogravimetric Analysis. Ind Eng Chem Res 53(20): 8651-8664.

89. Anson Brooks (2014) Ionic Liquids: Synthesis, Characterization and Applications. 


\section{Nanomedicine \& Nanotechnology Open Access}

90. Tsuda T, Chena C, Hussey CL (2018) Novel Analytical Techniques for Smart Ionic Liquid Materials. In: Ali Eftekhari (EDs.), Ionic Liquid Devices chapter 1, Royal Society of Chemistry, pp: 1-19.

91. Kuwabata S, Torimoto T, Imanishi A, Tsuda T (2013) chapter 23.

92. Imai Y, Abe H, Yoshimura Y (2009) X-ray Diffraction Study of Ionic Liquid Based Mixtures. J Phys Chem B 113(7): 2013-2018.

93. Camci MT, Aydogan P, Ulgut B, Kocabas C, Suzer S (2016) XPS enables visualization of electrode potential screening in an ionic liquid medium with temporal- and lateral-resolution. Phys Chem Chem Phys 18(41): 28434-28440.

94. Cowen LM, Atoyo J, Carnie MJ, Baran D, Schroeder BC (2017) Review-Organic Materials for Thermoelectric Energy Generation. ECS Journal of Solid State Science and Technology 6(3): 3080-3088.

95. Al Maimani M, Black JJ, Aldous L (2016) Achieving pseudo-'n-type p-type' in-series and parallel liquid thermoelectrics using all-iron thermoelectrochemical cells with opposite Seebeck coefficients. Electrochemistry Communications 72: 181-185.

96. Brittman S, Adhyaksa GWP, Garnet EC (2015) The expanding world of hybrid perovskites: materials properties and emerging applications. MRS Communications 5(1): 7-26.

97. Dupont MF, MacFarlane DR, Pringle JM (2017) Thermo-electrochemical cells for waste heat harvesting - progress and perspectives. Chem Commun 53(47): 6288-6302.

98. Han C, Li Z, Dou S (2014) Recent progress in thermoelectric materials. Chin Sci Bull 59(18): 2073 2091.

99. Abraham TJ, Mac Farlane DR, Pringle JM (2013) High Seebeck coefficient redox ionic liquid electrolytes for thermal energy harvesting. Energy Environ Sci 6(9): 2639-2645.

100. MacFarlane R, Tachikawa N, Forsyth M, Pringle JM, Howlett PC, et al. (2014) Energy applications of ionic liquids. Energy Environ Sci 7(1): 232-250.

101. Devaki SJ, Sasi R (2017) Ionic Liquids/Ionic Liquid Crystals for Safe and Sustainable Energy Storage Systems. In: Scott Handy (Eds.), Progress and Developments in Ionic Liquids chapter 14.
102. Hasan SW, Said SM, Sabri MFM, Abu Bakar AS, Hashim NA, et al. (2016) scientific reports 6: 2932829339.

103. Chum HL, Osteryoung RA (1980) Review of Thermally Regenerative Electrochemical Systems.

104. Abraham TJ, MacFarlane DR, Pringle JM (2011) Seebeck coefficients in ionic liquids -prospects for thermo-electrochemical cells. Chem Commun 47(22): 6260-6262.

105. Abrahama TJ, MacFarlane DR, Baughman RH, Jin L, Li $\mathrm{N}$, et al. (2013) Towards ionic liquid-based thermoelectrochemical cells for the harvesting of thermal energy. Electrochimica Acta 113(15): 87-93.

106. Aldous L, Black JJ, Elias MC, Ge'linasc B, Rochefort D (2017) Enhancing thermoelectrochemical properties by tethering ferrocene to the anion or cation of ionic liquids: altered thermodynamics and solubility. Phys Chem Chem Phys 19(35): 24255-24263.

107. Black JJ, Murphy T, Atkin R, Dolana A, Aldous L (2016) The thermoelectrochemistry of lithiumglyme solvate ionic liquids: towards waste heat harvesting. Phys Chem Chem Phys 18(30): 2076820777.

108. Abraham TJ (2013) School of Chemistry, Monash University, Ionic Liquid Electrolytes in Thermoelectrochemical Cells.

109. Cabrala D, Howlettb PC, Pringleb JM, Zhanga X, MacFarlane D (2015) Electrochemistry of tris(2,2'bipyridyl) cobalt(II) in ionic liquids and aprotic molecular solvents on glassy carbon and platinum electrodes. Electrochimica Acta 180: 419-426.

110. Siddique TA, Balamurugan S, Said SM, Sairib NA, Normazlan WMDW (2016) Synthesis and characterization of protic ionic liquids as thermoelectrochemical materials. RSC Adv 6(22): 18266-18278.

111. Placke T, Fromm O, Lux SF, Bieker P, Rothermel S, et al. (2012) Reversible Intercalation of Bis(trifluoromethanesulfonyl)imide Anions from an Ionic Liquid Electrolyte into Graphite for High Performance Dual-Ion Cells. Journal of The Electrochemical Society 159(11): 1755-1765.

112. Carlin RT, Delong HC, Fuller J, Trulove PC (1994) Dual Intercalating Molten Electrolyte Batteries. Journal of the Electrochemical Society 141(7): 73-76. 


\section{Nanomedicine \& Nanotechnology Open Access}

113. Agiorgousis ML, Sun Y, Zhang S (2017) The Role of Ionic Liquid Electrolyte in an Aluminum-Graphite Electrochemical Cell. ACS Energy Lett 2(3): 689-693.

114. Choia N, Leea Y, Kima S, Shina S, Kang Y (2010) Improving the electrochemical properties of
graphite/LiCoO 2 cells in ionic liquid-containing electrolytes. Journal of Power Sources 195(8): 23682371. 